\section{Glucosinolate Enhancement in Cabbage Induced by Jasmonic Acid Application}

\author{
Vincent A. Fritz ${ }^{1}$
}

Southern Research and Outreach Center, University of Minnesota, 35838 120th Street, Waseca, MN 56093; and the Department of Horticultural Science, University of Minnesota, 1970 Folwell Avenue, St. Paul, MN 55108

Veronica L. Justen

Department of Horticultural Science, University of Minnesota, 1970 Folwell Avenue, St. Paul, MN 55108

Ann M. Bode and Todd Schuster

Hormel Institute, University of Minnesota, 801 16th Avenue NE, Austin, MN 55912

\section{Min Wang \\ Southern Research and Outreach Center, University of Minnesota, 35838 120th Street, Waseca, MN 56093}

Additional index words. Brassica oleracea, jasmonic acid, glucosinolates, secondary compounds, HPLC

\begin{abstract}
Glucosinolates (GSL) are bioactive compounds found in cruciferous vegetables that have been shown to have chemopreventive benefits for human health. The objective of this study was to determine whether foliar application of jasmonic acid (JA) increases glucosinolate accumulation and yield in cabbage (Brassica oleracea L. Capitata group). Field studies were conducted in 2004 and 2005 with a green ('Quisto') and red ('Ruby Perfection') cabbage cultivar. Foliar JA application rates were $0.1 \mathrm{~mm}, 0.2 \mathrm{~mm}$, and split application of $0.2 \mathrm{mM} \mathrm{JA}$ with surfactant, surfactant control, and water control. Yield of both cabbage cultivars was not changed by JA application in both years of the study. In both years, 'Ruby Perfection' had significantly higher glucosinolate concentrations than 'Quisto' with sinigrin being the predominant glucosinolate in both varieties. JA application consistently increased sinigrin, gluconapin, and glucoiberin concentrations across cultivars and years of the study. JA application also increased progoitrin and total GSL concentrations, but the effect was inconsistent between years and cultivars. In most cases, a split application of $0.2 \mathrm{~mm} \mathrm{JA}$ resulted in the highest GSL accumulation. GSL accumulation was significantly higher in 2005 than 2004 for both cultivars. Climatic data suggest that annual differences in temperature may have influenced the variability in glucosinolate concentration in cabbage.
\end{abstract}

Jasmonic acid (JA) and its volatile equivalent, methyl jasmonate (MeJA), are plant hormones involved in chemical and physiological defense responses. MeJA and JA have no direct impact on plant herbivores, but instead contribute to an intracellular signal cascade that elicits secondary metabolite production important for plant defense (Wasternack and Parthier, 1997). Exogenous JA and MeJA applications have been used to induce plant responses resulting in resistance to attack from nematodes (Cooper et al., 2005; Oka et al., 1999), insect pests (Omer et al., 2000, 2001), and plant pathogens (Brader et al., 2001). Exogenous jasmonate application has also been shown to reduce chilling injury (Gonzalez-Aguilar et al.,

Received for publication 13 Apr. 2010. Accepted for publication 16 June 2010.

${ }^{1}$ To whom reprint requests should be addressed; e-mailvafritz@umn.edu.

2003) and enhance accumulation of several classes of secondary compounds (as reviewed by Memelink et al., 2001).

Glucosinolates (GSLs) are a class of secondary metabolites present in members of the Brassicaceae family. GSLs are constitutively produced thioglycosidic compounds with aliphatic, aromatic, or indolic groups depending on which modified amino acid they contain. Upon hydrolysis with myrosinase, a $\beta$-thioglucosidase, GSLs yield bioactive compounds, including volatile isothiocyanates. GSLs and their subsequent hydrolysis products are deterrents to herbivores and generalist insects and inhibit pathogen growth (reviewed by Chew, 1988); they also have potent benefits for human health (Zhang et al., 1992). For example, glucobrassicin (indole-3-ylmethyl glucosinolate), the primary glucosinolate in cabbage (Rosen et al., 2005), and its isothiocyanate derivative, indole-3carbinol, have been shown to have potent chemopreventive properties (Jinno et al.,
1999; reviewed by van Poppel et al., 1999). Increasing GSL concentration in cabbage with cultural practices such as exogenous JA application would increase the efficiency of GSL-producing plants and have implications for human health and the nutraceutical industry.

JA-induced GSL accumulation has been documented in several plant species. Exogenous JA and MeJA application has been shown to increase both the accumulation of indolic GSLs and their biosynthetic gene transcript levels in Arabidopsis (Mewis et al., 2005; Mikkelsen et al., 2003). Jasmonate application has also been documented to enhance aromatic glucosinolate levels such as glucotropaeolin (Wielanek and Urbanek, 2006). Additionally, research has shown that jasmonate-induced increases in total GSL accumulation in Brassica crops do not result in significant losses in biomass (Cipollini and Sipe, 2001; van Dam et al., 2004).

Although previous studies indicate that JA-induced GSL enhancement is possible, these studies have not been performed under field conditions using heading cabbage nor have they addressed how JA-induced GSL levels can vary between cultivars of a specific crop. Under normal field conditions, GSL levels in cabbage are, in part, cultivardependent with red cabbage containing more GSLs than green cabbage (Rosen et al., 2005). We wanted to examine how JA-induced GSL enhancement under field production conditions differs between commercially grown cabbage cultivars. Our objectives were: 1) to examine differences in GSL concentration in field-grown red and green cabbage exposed to various foliar application rates of JA; and 2) to determine the effect of exogenous JA application on cabbage yield. We chose to quantify both indolic and aliphatic GSLs individually because these GSL groups are under separate genetic control based on amino acid and therefore may be under different environmental controls (as reviewed by Grubb and Abel, 2006).

\section{Materials and Methods}

Field studies were conducted in 2004 and 2005 at the University of Minnesota Southern Research and Outreach Center in Waseca, $\mathrm{MN}$, on a Webster Clay Loam (fine-loamy, mixed superactive typic endoaquoll) soil. 'Quisto' (Rogers NK, Boise, ID) green cabbage and 'Ruby Perfection' (American Takii, Salinas, CA) red cabbage seeds were seeded in 48 -count cell $(53 \times 27 \mathrm{~cm})$ trays containing moist soilless seeding media (SunGro Horticulture; Sunshine SB-300 Universal, Bellevue, WA) and grown in the greenhouse until transplanting. 'Ruby Perfection' was chosen for this study because it exhibited inherently high glucosinolate concentrations in preliminary studies (unpublished data). 'Quisto' was chosen for comparison because it is a widely grown cabbage cultivar in the upper Midwest. Four-week-old seedlings were transplanted on 1 July 2004 and 8 July 2005 in a split plot design consisting of four 
replications of cabbage cultivar subplots within randomized main plots of JA rate in each replication. Each subplot was $7.62 \mathrm{~m}$ long with $0.3-\mathrm{m}$ spacing between plants and $0.76 \mathrm{~m}$ between subplots. The entire site of the experiments was fertilized before transplanting with $132 \mathrm{~kg}$ nitrogen/ha as urea. Preplant selected soil properties 2004-2005 were as follows ( 0 to $15 \mathrm{~cm}): \mathrm{pH}$ (1 soil: 1 water) of 6.6 to 7.1, Bray phosphorus, 45 to $43 \mathrm{mg} \cdot \mathrm{kg}^{-1}$, and ammonium extractable potassium, 145 to $137 \mathrm{mg} \cdot \mathrm{kg}^{-1}$. Plots were routinely irrigated using drip tape (T-tape; T-Systems International, Inc., San Diego, CA) that ensured at least $2.52 \mathrm{~cm}$ water weekly.

Jasmonic acid (Sigma-Aldrich, St. Louis, MO) was prepared in water with Tween ${ }^{\circledR} 20$ surfactant (Sigma-Aldrich) and applied at the following concentrations: $0.1 \mathrm{~mm}, 0.2 \mathrm{~mm}$, and $0.2 \mathrm{~mm}$ split application. The three JA treatment rates plus a surfactant and water control were applied as a foliar spray in excess at $31 \mathrm{~cm}$ above the plants using a backpack sprayer fitted with a cone nozzle at $138 \mathrm{kPa}$ pressure. JA application began at heading initiation (when youngest leaves stopped to unfold: 8 Aug. 2004 and 15 Aug. 2005) to allow for better penetration of JA into the apical meristem. The second application of the $0.2 \mathrm{~mm}$ split treatment was applied 20 Aug. 2004 and 22 Aug. 2005.

Cabbage plants were harvested 11 Oct. 2004 and 30 Sept. 2005. Six cabbage heads were harvested from each subplot for yield measurements. From the heads harvested, two were quartered to obtain duplicate subsamples for dry weight and GSL determination.

Sample preparation. Extraction and GSL quantification was performed as per Hecht et al. (2004) using modifications from Rosen et al. (2005). Briefly, cabbage subsamples were weighed and boiled in three times the weight per volume of boiling water for $5 \mathrm{~min}$ to deactivate myrosinase. Boiled samples were macerated in a blender for $2 \mathrm{~min}$. Aliquots of blended samples were stored at $-20{ }^{\circ} \mathrm{C}$ until homogenization. A 5-mL aliquot of the blended sample was homogenized using a Polytron PT 1300D (Kinematica Ag, Lucerne, Switzerland) set at 12,000 $\mathrm{rpm}$ at $4{ }^{\circ} \mathrm{C}$ for $2 \mathrm{~min}$ and then centrifuged for $15 \mathrm{~min}$ at $2000 \mathrm{~g}_{\mathrm{n}}, 4^{\circ} \mathrm{C}$. Desulphoglucosinolate extraction was performed using conditioned solid phase strong anion exchange (SAX) columns (Sigma-Aldrich). To desulphate, samples were incubated with sulphatase (S-9626; Sigma-Aldrich) on SAX columns for $\approx 15 \mathrm{~h}$ then eluted with $3 \mathrm{~mL}$ water and the collected volume was determined by weight. Further washing of the columns yielded no additional desulphated glucosinolates confirming complete elution. Eluent was stored at $-20{ }^{\circ} \mathrm{C}$ until highperformance liquid chromatography (HPLC) analysis.

High-performance liquid chromatography analysis. (HPLC analyses were performed on two cabbage plants per plot with each plant extract analyzed in triplicate. HPLC analyses and GSL quantification were performed according to Rosen et al. (2005). Briefly, $100 \mu \mathrm{L}$ of eluent was injected through a Beckman 507e autoinjector onto a Luna C18, 5 $\mu \mathrm{m}, 250 \times 4.6-\mathrm{mm}$ column (Phenomenex, Torrance, CA). HPLC analyses were performed on a Beckman 126 Solvent Module equipped with a Beckman 168 Diode Array Detector set at $\lambda=229 \mathrm{~nm}$. HPLC analysis was conducted with a flow rate of 1.0 $\mathrm{mL} \cdot \mathrm{min}^{-1}$ using the following gradient: solvent $\mathrm{A}=$ water and $\mathrm{B}=$ acetonitrile; 0 to $2 \mathrm{~min}$, $95 \% \mathrm{~A}, 5 \% \mathrm{~B} ; 2$ to $30 \mathrm{~min}, 85 \% \mathrm{~A}, 15 \% \mathrm{~B} ; 30$ to $35 \mathrm{~min}, 35 \% \mathrm{~A}, 65 \% \mathrm{~B} ; 35$ to $37 \mathrm{~min}, 10 \%$ A, $90 \% \mathrm{~B}$; and 37 to $60 \mathrm{~min}, 95 \% \mathrm{~A}, 5 \%$ B. Chromatographic data were integrated with Beckman System Gold Noveaux software. Desulphoglucosinolates were identified based on retention time and comparison with a mixture of known standards (courtesy of R. Mithen, Norwich, U.K.). Peak areas were adjusted according their response factor (EU, 1990) and then used to calculate desulphoglucosinolate concentrations based on comparison with a desulphosinigrin standard curve.

Data were analyzed with R 2.0.1 (R Foundation for Statistical Computing, Vienna, Austria). The significance of differences among treatments, cultivar, and years was assessed by fixed-factor analysis of variance. Mean values were considered significantly different at $P<$ 0.05 as determined by Tukey's honestly significant difference.

\section{Results and Discussion}

Yield. The main effect of cultivar was a significant factor influencing yield with 'Quisto' green cabbage producing higher dry weight yields, on average $43 \%$ greater than 'Ruby Perfection' red cabbage (Table 1). Rosen et al. (2005) also observed similar yield differences between red and green cabbage. In their study on the effects of nitrogen and sulfur fertility on yield and GSL concentration, 'Grand Slam' green cabbage yielded $48 \%$ more than 'Vorox' red cabbage on a dry weight basis. The main effects of JA treatment and year did not significantly affect cabbage yield in either cultivar. This is consistent with previous studies that showed no effect of exogenous JA on plant yield (Cipollini and Sipe, 2001; van Dam et al., 2004).

Glucosinolate concentration. JA treatment was a significant factor influencing glucoiberin (GI), sinigrin (SN), and gluconapin (GNP) concentrations (Table 1). JA did

Table 1. Yield and glucosinolate concentration of cabbage varieties across years, cultivars, and jasmonic acid (JA) treatments. ${ }^{2}$

\begin{tabular}{|c|c|c|c|c|c|c|c|c|c|}
\hline \multirow[b]{2}{*}{ Source of variation ${ }^{y}$} & \multirow[b]{2}{*}{ Dry wt yield $(\mathrm{kg})$} & \multicolumn{8}{|c|}{ Glucosinolate concn $(\mu \mathrm{mol} / 100 \mathrm{~g}$ fresh weight $)$} \\
\hline & & GI & PRO & GR & SN & GF & GNP & GB & Total \\
\hline Water control & 0.73 & $16.5 \mathrm{~b}^{\mathrm{y}}$ & 12.0 & 18.8 & $23.9 \mathrm{~b}$ & 10.4 & $8.7 \mathrm{~b}$ & 12.8 & 105.3 \\
\hline $0.2 \mathrm{~mm}$ & 0.70 & $18.7 \mathrm{ab}$ & 14.9 & 20.3 & $26.6 \mathrm{ab}$ & 12.4 & $10.1 \mathrm{ab}$ & 11.5 & 118.3 \\
\hline $0.2 \mathrm{~mm}$ split & 0.66 & $19.8 \mathrm{a}$ & 18.2 & 25.4 & $32.2 \mathrm{a}$ & 12.1 & $13.9 \mathrm{a}$ & 13.2 & 137.4 \\
\hline Significance & & * & *x & & * & & $*$ & & $* \mathrm{x}$ \\
\hline 2005 & 0.72 & 30.9 & 20.8 & 37.5 & 39.9 & 13.9 & 15.4 & 20.1 & 182.6 \\
\hline Significance & & *x & *x & *x & *x & *x & $* \mathrm{x}$ & *x & *x \\
\hline \multicolumn{10}{|l|}{ Cultivar } \\
\hline Quisto & $0.83 \mathrm{a}$ & 19.8 & 4.0 & 1.9 & 31.1 & 0.1 & 1.5 & 3.0 & 62.7 \\
\hline Ruby Perfection & $0.58 \mathrm{~b}$ & 17.5 & 25.8 & 42.2 & 23.2 & 24.1 & 19.6 & 22.3 & 178.7 \\
\hline Significance & & $* \mathrm{x}$ & $* \mathrm{x}$ & $* \mathrm{x}$ & *x & $* \mathrm{x}$ & $* x$ & $* x$ & $* \mathrm{x}$ \\
\hline \multicolumn{10}{|l|}{ Interactions } \\
\hline
\end{tabular}

${ }^{2}$ Yield represents the dry weight $(\mathrm{kg})$ of six randomly selected cabbage heads at time of harvest.

'Means with different letters within each column and source of variation are significantly different at $P \leq 0.05$ as determined by Tukey's honestly significant difference. GI glucoiberin; PRO = progoitrin; GR = glucoraphanin; GF = gluconapoleiferin; GNP = gluconapin; GB = glucobrassicin.

${ }^{\mathrm{x}}$ Mean separations on main effects were not performed due to the presence of significant interactions.

*, NS $=$ Significant at $P \leq 0.05$ or nonsignificant. 
not have a significant effect on gluconapoleiferin (GF) or glucobrassicin (GB) concentration in either cultivar or year of the study. In all cases in which JA was significant, control plots yielded lower GSL concentrations than plots treated with JA. For SN and GNP, the $0.2 \mathrm{~mm}$ split treatment of JA yielded the highest GSL concentrations resulting in $\approx 35 \%$ more $\mathrm{SN}$ and $60 \%$ more GNP than the water control. The interactive effects of JA $\times$ cultivar and JA $\times$ year were significant for progoitrin (PRO) and total GSL concentrations, respectively. JA did not significantly affect total GSL concentrations in 2004, but did significantly affect total GSLs in 2005 with the $0.2 \mathrm{~mm}$ split application yielding $\approx 37 \%$ higher total GSL concentration than the water control treatment (Table 2). In the case of PRO, JA treatment did not affect PRO in 'Quisto' but significantly affected PRO in 'Ruby Perfection' with the $0.2 \mathrm{~mm}$ split treatment yielding $\approx 60 \%$ more PRO than the water control treatment (Table 3 ). In most instances, treatment with JA did result in significant increases in GSL concentration as compared with the water control treatment; however, only in the case of SN did treatment with JA result in significantly higher GSL concentration than the surfactant control (Table 1).

Our results are partially consistent with previous studies that have reported increased GSL accumulation after exogenous JA or MeJA application (e.g., Loivamaki et al., 2004; van Dam et al., 2004;). Although we did observe consistent JA-induced increases in some aliphatic GSLs, the lack of a JAinduced increase in GB concentration observed in our study was inconsistent with several other studies in which significant increases in indolic GSLs were observed after JA application (Bodnaryk, 1994; van Dam et al., 2004). Although hormone concentrations applied in these studies were similar to those applied to the plants in our study, the plants in other studies were harvested much sooner after the JA or MeJA treatment than in our study. Previous studies that found significant increases in GSLs after exogenous JA or MeJA treatment harvested tissue for GSL analysis within $7 \mathrm{~d}$ after the final JA treatment. Additionally, Mikkelsen et al. (2003) found both indolic and aliphatic GSL biosynthetic gene transcripts to be upregulated within $24 \mathrm{~h}$ after JA application. Plants in our study were not harvested until 37 to $46 \mathrm{~d}$ after treatment in 2005 and 52 to $64 \mathrm{~d}$ after treatment in 2004. Bodnaryk (1994) found that in seedlings treated with 5 nmol/plant MeJA, jasmonate-induced GSLs reached maximum levels $7 \mathrm{~d}$ after treatment, after which the induced GSL increase of treated plants as compared with controls was decreased substantially. This loss of jasmonate-induced response is unlikely only observed in plants treated with MeJA, but JA as well. Bodnaryk (1994) found that $24 \mathrm{~h}$ after application, jasmonate-induced GSL accumulation in B. napus was the same for MeJA and JA-treated plants. Therefore, it is plausible that jasmonate-induced GSL production in our field-grown plants was mitigated, particularly in GB, because of the length of time between application and harvest. Perhaps delaying the JA application time to 1 week before harvest would have produced a more significant effect on JAinduced aliphatic GSL concentration and a significant effect on JA-induced GB concentration. The degradation of jasmonate-

Table 2. The interactive effects of jasmonic acid (JA) treatment, cultivar, and year on total glucosinolate concentration in cabbage.

\begin{tabular}{|c|c|c|}
\hline \multirow[b]{2}{*}{ Source of variation ${ }^{z}$} & \multicolumn{2}{|c|}{ Total GSL concn $(\mu \mathrm{mol} / 100 \mathrm{~g}$ fresh weight $)$} \\
\hline & $2004^{y}$ & 2005 \\
\hline \multicolumn{3}{|l|}{ JA treatment } \\
\hline Water control & $57.7 \mathrm{aB}$ & $155.9 \mathrm{bA}$ \\
\hline Surfactant control & $54.9 \mathrm{aB}$ & $182.9 \mathrm{abA}$ \\
\hline $0.1 \mathrm{~mm}$ & $67.1 \mathrm{aB}$ & $183.5 \mathrm{abA}$ \\
\hline $0.2 \mathrm{~mm}$ & $60.6 \mathrm{aB}$ & $176.1 \mathrm{abA}$ \\
\hline $0.2 \mathrm{~mm}$ split & $61.9 \mathrm{aB}$ & $212.8 \mathrm{aA}$ \\
\hline \multicolumn{3}{|l|}{ Cultivar } \\
\hline Quisto & $24.4 \mathrm{bB}$ & $101.1 \mathrm{bA}$ \\
\hline Ruby Perfection & $95.4 \mathrm{aB}$ & $262.1 \mathrm{aA}$ \\
\hline \multicolumn{3}{|c|}{$\begin{array}{l}\text { "Means with different lowercase letters within each column and source of variation are significantly } \\
\text { different at } P \leq 0.05 \text { as determined by Tukey's honestly significant difference. } \\
\text { 'Means with different uppercase letters within each row are significantly different at } P \leq 0.05 \text { as } \\
\text { determined by Tukey's honestly significant difference. }\end{array}$} \\
\hline \multicolumn{3}{|c|}{$\begin{array}{l}\text { Table } 3 . \text { The interactive effects of jasmonic acid (JA) treatment and cultivar on progoitrin concentration } \\
\text { in cabbage. }\end{array}$} \\
\hline \multirow[b]{2}{*}{ JA treatment } & \multicolumn{2}{|c|}{ Progoitrin concn $(\mu \mathrm{mol} / 100 \mathrm{~g}$ fresh weight $)$} \\
\hline & Quisto & Ruby Perfection \\
\hline Water control & $3.5 \mathrm{a}^{\mathrm{z}}$ & $20.0 \mathrm{~b}$ \\
\hline Surfactant control & $3.6 \mathrm{a}$ & $25.5 \mathrm{ab}$ \\
\hline $0.1 \mathrm{~mm}$ & $4.5 \mathrm{a}$ & $25.5 \mathrm{ab}$ \\
\hline $0.2 \mathrm{~mm}$ & $3.8 \mathrm{a}$ & $26.0 \mathrm{ab}$ \\
\hline $0.2 \mathrm{~mm}$ split & $4.7 \mathrm{a}$ & $31.8 \mathrm{a}$ \\
\hline
\end{tabular}

${ }^{\mathrm{z}}$ Means with different letters within each column are significantly different at $P \leq 0.05$ as determined by Tukey's honestly significant difference. induced GSLs in field-grown samples needs to be addressed in future research by optimizing JA application time and rate to achieve greater levels of jasmonate-induced GSLs in harvested crops.

The interactive effects of year $\times$ cultivar were significant for total GSL and individual GSL concentrations. Despite this interaction, mean total GSL concentrations were more than three times higher in red cabbage 'Ruby Perfection' than in green cabbage 'Quisto' across years of the study (Table 2). This result is consistent with that of Rosen et al. (2005) who found 'Vorox' red cabbage had between $45 \%$ and $64 \%$ higher GSL concentrations than 'Grand Slam' green cabbage. Despite the significance of the year $\times$ cultivar interaction, total GSL concentrations were significantly lower in 2004 than 2005 in both cultivars, suggesting that environmental differences between the 2 years resulted in variable GSL accumulation (Table 2).

Inconsistent GSL production in cabbage between both years in this study may have been the result of annual differences in climate. In our study, higher GSL concentrations were found in cabbage grown in 2005 . The mean air temperature in Aug. 2004 was $5{ }^{\circ} \mathrm{C}$ cooler than in Aug. 2005. Additionally, mean soil temperature at $5-\mathrm{cm}$ soil depth in Aug. 2004 was $7{ }^{\circ} \mathrm{C}$ cooler than in Aug. 2005. Temperature has been shown to influence GSL content with higher temperatures leading to increased GSL concentrations. Nilsson et al. (2006) noted that annual differences in GSL concentration in cauliflower were correlated with temperature where a $1{ }^{\circ} \mathrm{C}$ higher mean temperature yielded higher GSL concentrations. Velasco et al. (2007) also noted a similar response in kale, in which plants grown in colder locations yielded lower GSL concentrations, although the relationship between temperature and GSL concentration in this study may have been confounded with effects from frost. Charron et al. (2005) found a positive correlation between temperature 2 to 4 weeks before harvest and total and indolic GSL concentrations in several Brassica sp. vegetables. A controlled environment study supported field-based correlations between temperature and GSL concentration, revealing that increased temperature results in elevated levels of GSLs in rapid-cycling B. oleracea (Charron and Sams, 2004). Radovich et al. (2005) also noted a positive correlation between air temperature and GSL concentration in cabbage. The authors attributed this temperature-related increase in GSL accumulation to increased stress under supraoptimal temperatures.

\section{Conclusions}

Cabbage yield was unaffected by JA treatment. Year was a significant factor influencing GSL concentration in both cabbage cultivars, possibly as a result of annual differences in soil and air temperatures. Cultivar was also a significant factor for GSL concentration with 'Ruby Perfection' consistently having higher GSL levels than 
'Quisto'. JA treatment did influence individual aliphatic GSL and total GSL concentrations in cabbage in some instances but did not affect indolic GSL concentrations. The variability in JA-induced GSL accumulation observed in our study may have been the result of the time interval between JA application and harvest, which was much longer than intervals used in previous studies. Future research should address the optimum JA application time and rate needed to enhance GSL accumulation in a production scale system.

\section{Literature Cited}

Bodnaryk, R.P. 1994. Potent effect of jasmonates on indole glucosinolates in oilseed rape and mustard. Phytochemistry 35:301-305.

Brader, G., E. Tas, and E.T. Palva. 2001. Jasmonatedependent induction of indole glucosinolates in Arabidopsis by culture filtrates of the nonspecific pathogen Erwinia carotovora. Plant Physiol. 126:849-860.

Charron, C.S. and C.E. Sams. 2004. Glucosinolate content and myrosinase activity in rapidcycling Brassica oleracea grown in a controlled environment. J. Amer. Soc. Hort. Sci. 129:321330.

Charron, C.S., A.M. Saxton, and C.E. Sams. 2005. Relationship of climate and genotype to seasonal variation in the glucosinolate-myrosinase system. I. Glucosinolate content in ten cultivars of Brassica oleracea grown in fall and spring seasons. J. Sci. Food Agr. 85:671-681.

Chew, F.S. 1988. Biological effects of glucosinolates, p. 155-181. In: Cutler, H.G. (ed.). Biologically active natural products: Potential use in agriculture, Amer. Chem. Soc., Washington, DC.

Cipollini, D.F. and M.L. Sipe. 2001. Jasmonic acid treatment and mammalian herbivory differentially affect chemical defenses and growth of wild mustard (Brassica kaber). Chemoecology 11:137-143.

Cooper, W.R., L. Jia, and L. Goggin. 2005. Effects of jasmonate-induced defenses on root-knot nematode infection of resistant and susceptible tomato cultivars. J. Chem. Ecol. 31:19531967.
EU. 1990. Off. J Eur Commun. L 170:03.07. p. 27-34.

Gonzalez-Aguilar, G.A., J.G. Buta, and C.Y. Wang. 2003. Methyl jasmonate and modified atmosphere packaging (MAP) reduce decay and maintain postharvest quality of papaya 'Sunrise'. Postharvest Biol. Technol. 28:361370.

Grubb, C.D. and S. Abel. 2006. Glucosinolate metabolism and its control. Trends Plant Sci. 11: 89-100.

Hecht, S.S., S.G. Carmella, P.M.J. Kenney, S.H. Low, K. Arakawa, and M.C. Yu. 2004. Effects of cruciferous vegetable consumption on urinary metabolites of the tobacco-specific lung carcinogen 4-(methyinitrosamino)-1-(3pyridyl)-1-butanone in Singapore Chinese. Cancer Epidemiol. Biomarkers Prev. 13:9971004.

Jinno, H., M.G. Steiner, R.G. Mehta, M.P. Osborne, and N.T. Telang. 1999. Inhibition of aberrant proliferation and induction of apoptosis in HER$2 /$ neu oncogene transformed human mammary epithelial cells by $\mathrm{N}$-(4-hydroxyphenyl)retinamide. Carcinogenesis 20:229-236.

Loivamaki, M., J.K. Holopainen, and A.M. Nerg. 2004. Chemical changes induced by methyl jasmonate in oilseed rape grown in the laboratory and in the field. J. Agr. Food Chem. 52: 7607-7613.

Memelink, J., R. Verpoorte, and J.W. Kijne. 2001. ORCAnization of jasmonate-responsive gene expression in alkaloid metabolism. Trends Plant Sci. 6:212-219.

Mewis, I., H.M. Appel, A. Hom, R. Raina, and J.C. Schultz. 2005. Major signaling pathways modulate Arabidopsis glucosinolate accumulation and response to both phloem-feeding and chewing insects. Plant Physiol. 138:11491162.

Mikkelsen, M.D., B.L. Petersen, E. Glawischnig, A.B. Jensen, E. Andreasson, and B.A. Halkier. 2003. Modulation of CYP79 genes and glucosinolate profiles in Arabidopsis by defense signaling pathways. Plant Physiol. 131:298308

Nilsson, J., K. Olsson, G. Engqvist, J. Ekvall, M. Olsson, M. Nyman, and B. Akesson. 2006. Variation in the content of glucosinolates, hydroxycinnamic acids, carotenoids, total antioxidant capacity and low-molecular-weight carbohydrates in Brassica vegetables. J. Sci. Food Agr. 86:528-538.

Oka, Y., Y. Cohen, and Y. Spiegel. 1999. Local and systemic induced resistance to the root-knot nematode in tomato by DL-beta-amino-n-butyric acid. Phytopathology 89:1138-1143.

Omer, A.D., J. Granett, R. Karban, and E.M. Villa. 2001. Chemically-induced resistance against multiple pests in cotton. Int. J. Pest Manage. 47: $49-54$.

Omer, A.D., J.S. Thaler, J. Granett, and R. Karban. 2000. Jasmonic acid induced resistance in grapevines to a root and leaf feeder. J. Econ. Ent. 93:840-845.

Radovich, T.J.K., M.D. Kleinhenz, J.G. Streeter, A.R. Miller, and J.C. Scheerens. 2005. Planting date affects total glucosinolate concentrations in six commercial cultivars of cabbage (Brassica oleracea L., Capitata group). HortScience 40:106-110.

Rosen, C.J., V.A. Fritz, G.M. Gardner, S.S. Hecht, S.G. Carmella, and P.M. Kenney. 2005. Cabbage yield and glucosinolate concentrations as affected by nitrogen and sulfur fertility. HortScience 40:1493-1498.

van Dam, N.M., L. Witjes, and A. Svatos. 2004 Interactions between aboveground and belowground induction of glucosinolates in two wild Brassica species. New Phytol. 161:801-810.

van Poppel, G., D.T. Verhoeven, H. Verhagen, and R.A. Goldbohm. 1999. Brassica vegetables and cancer prevention. Epidemiology and mechanisms. Adv. Exp. Med. Biol. 472:159-168

Velasco, P., M.E. Cartea, C. Gonzalez, M. Vilar, and A. Ordas. 2007. Factors affecting the glucosinolate content of kale (Brassica oleracea L., Acephala group). J. Agr. Food Chem. 55: 955-962.

Wasternack, C. and B. Parthier. 1997. Jasmonatesignalled plant gene expression. Trends Plant Sci. 2:302-307.

Wielanek, M. and H. Urbanek. 2006. Enhanced glucotropaeolin production in hairy root cultures of Tropaeolum majus L. by combining elicitation and precursor feeding. Plant Cell Tissue Organ Cult. 86:177-186.

Zhang, Y.S., P. Talalay, C.G. Cho, and G.H. Posner 1992. A major inducer of anticarcinogenic protective enzymes from broccoli-Isolation and elucidation of structure. Proc. Natl. Acad. Sci. USA 89:2399-2403. 